\title{
Anti-proliferative effects of Chinese herb Cornus officinalis in a cell culture model for estrogen receptor-positive clinical breast cancer
}

\author{
N.T. TELANG ${ }^{1}$, G. $\mathrm{LI}^{2}$, D.W. SEPKOVIC ${ }^{3}$, H.L. BRADLOW ${ }^{3}$ and G.Y.C. WONG ${ }^{2,4}$ \\ ${ }^{1}$ Cancer Prevention Research Program, Palindrome Liaisons, Montvale, NJ; ${ }^{2}$ American Foundation for \\ Chinese Medicine, NY; ${ }^{3}$ The David and Alice Jurist Institute for Research, Hackensack, NJ; \\ ${ }^{4}$ Department of Integrative Medicine, Beth Israel Medical Center, NY, USA
}

Received January 21, 2011; Accepted September 22, 2011

DOI: $10.3892 / \mathrm{mmr} .2011 .617$

\begin{abstract}
Selective estrogen receptor modulators and a combination of mechanistically distinct chemotherapeutic agents represent conventional therapeutic interventions for estrogen receptor-positive $\left(\mathrm{ER}^{+}\right)$clinical breast cancer. Longterm treatment with these agents is associated with acquired tumor resistance and other adverse side effects that impact on patient compliance. Herbal medicines are being widely used in complementary and alternative medicine. However, long-term safety and efficacy of the use of herbal medicines, as well as their interaction with conventional endocrine and chemotherapeutic drug regimens remain largely unknown. The present study utilized a human cell culture model for $\mathrm{ER}^{+}$ clinical breast cancer to examine the potential therapeutic efficacy of an aqueous extract prepared from the fruit of popular Chinese herb Cornus officinalis (CO), also known as Fructus cornii. The human mammary carcinoma-derived MCF-7 cell line represented the model. Status of anchorage-independent growth and cellular metabolism of $17 \beta$-estradiol $\left(\mathrm{E}_{2}\right)$ represented the quantitative end-point biomarkers for efficacy. MCF-7 cells adapted for growth in serum-depleted medium ( $0.7 \%$ serum, $<1 \mathrm{nM} \mathrm{E}_{2}$ ) retained their endocrine responsiveness as evidenced by growth promotion by physiological levels of $\mathrm{E}_{2}$, and growth inhibition by the selective ER modulator tamoxifen at the clinically achievable concentrations. Treatment of MCF-7 cells with $\mathrm{CO}$ resulted in inhibition of $\mathrm{E}_{2}$-stimulated growth in a dose-dependent manner. Similarly, $\mathrm{CO}$ treatment also produced a dose-dependent progressive reduction in the number of anchorage-independent colonies, indicating effective reduction of the carcinogenic risk. Treatment of MCF-7 cells with $\mathrm{CO}$ at a maximally effective cytostatic concentration resulted in a 5.1-fold increase in the formation of the
\end{abstract}

Correspondence to: Dr Nitin Telang, Cancer Prevention Research Program, Palindrome Liaisons, 10 Rolling Ridge Road, Suite B, Montvale, NJ 07645-1559, USA

E-mail: entitytoo@gmail.com

Key words: breast carcinoma, Chinese herb, estradiol metabolism anti-prolifertive $\mathrm{E}_{2}$ metabolite 2-hydoxyestrone (2- $\left.\mathrm{OHE}_{1}\right)$, a $63.6 \%$ decrease in the formation of the pro-mitogenic metabolite $16 \alpha$-hydroxestrone $\left(16-\alpha \mathrm{OHE}_{1}\right)$ and a $9.1 \%$ decrease in the formation of mitogenically inert metabolite estrone $\left(\mathrm{E}_{3}\right)$. These alterations led to a 14.5 -fold increase in the $2-\mathrm{OHE}_{1}: 16 \alpha-\mathrm{OHE}_{1}$, and a 3.3-fold increase in the $\mathrm{E}_{3}: 16 \alpha-\mathrm{OHE}_{1}$ ratios. These data validate a rapid cell culture-based mechanistic approach to prioritize efficacious herbal medicinal products for long-term animal studies and future clinical trials on $\mathrm{ER}^{+}$clinical breast cancer.

\section{Introduction}

Invasive breast cancer remains one of the leading causes of mortality in the US. The American Cancer Society projections for invasive breast cancer incidence and mortality for 2012 estimate 230,480 newly diagnosed invasive breast cancer cases and 39,520 invasive breast cancer-related deaths (1). These projections emphasize a persistent need to identify new modalities for prevention/therapy of invasive breast cancer.

Conventional chemo-endocrine therapy with selective estrogen receptor modulators with or without combination chemotherapy using mechanistically distinct cytotoxic drugs continues to represent the treatment of choice for hormone responsive estrogen receptor-positive $\left(\mathrm{ER}^{+}\right)$clinical breast cancer. However, these modalities are frequently associated with acquired tumor resistance and/or adverse systemic toxicity, compromising long-term patient compliance $(2,3)$.

Complementary and alternative medicine, using herbal medicinal products, has acquired wide application in nonresponsive patients for a potential to reduce chemo-endocrine therapy-related toxicity (4-7). Most of the herbal medicinal products are available from health food stores as general health-improving nutritional supplements, and also from herbal medical practitioners. However, evidence for long-term safety and efficacy of herbal medicines remains to be systematically documented and, therefore, is currently equivocal.

Several herbal medicinal preparations have been noted to sensitize tumor cells to radiation therapy, enhance clinical efficacy of LAK/IL-12 based immunotherapy in cancer patients and represent an accessory modality of treatment for 
malignant tumor, immuno-deficiency and for the prevention of cancer radiation/chemotherapy-associated side effects (8-10). In this study, we investigated the anti-proliferative action on the human mammary carcinoma MCF-7 cells of the fruit of Cornus officinalis (CO), also known as Fructus cornii (FC), a popular Chinese herb of a nutritional nature. $\mathrm{CO}$ represents a major ingredient herb in some well-known traditional Chinese herbal mixtures.

The human mammary carcinoma-derived ER ${ }^{+} \mathrm{MCF}-7$ cell line represents a well-recognized pre-clinical model for hormone responsive clinical breast cancer. This model has been extensively used both as a cell culture approach, as well as an in vivo xenotransplant approach for pre-clinical efficacy studies on synthetic ER modulators and inhibitors of estrogen biosynthesis (11).

The present study utilized the MCF-7 cell culture model to examine the cellular and endocrine effects of $\mathrm{CO}$ that are relevant to growth inhibition of human breast cancer cells. The data generated from this study demonstrate that low doses of non-fractionated aqueous extract from $\mathrm{CO}$ exhibit progressive cytostatic growth arrest and reduction of carcinogenic risk in $17 \beta$-estradiol $\left(\mathrm{E}_{2}\right)$-stimulated $\mathrm{ER}^{+} \mathrm{MCF}-7$ cells. Furthermore, treatment of MCF-7 cells with $\mathrm{CO}$ at a maximally effective cytostatic concentration alters the cellular metabolism of $\mathrm{E}_{2}$ via distinct metabolic pathways. These data taken together validate the present cell culture model as a rapid mechanismbased approach to screen natural herbs for their therapeutic efficacy and prioritize promising lead agents for subsequent animal studies and clinical trials for breast cancer therapy.

\section{Materials and methods}

Cell line. The $\mathrm{ER}^{+}$human breast carcinoma MCF-7 cell line was originally obtained from the Michigan Cancer Foundation (Detroit, MI, USA). These cells were cultured in DME/F12 medium supplemented with $7 \%$ heat-inactivated fetal calf serum and recommended additives (12).

For the present experiments, MCF-7 cells were adapted for growth in serum-depleted medium by maintaining the cultures in the tissue culture medium supplemented with $0.7 \%$ serum for at least 5 passages. These stock cultures were routinely maintained in DME/F12 medium supplemented with $0.7 \%$ serum in an humidified atmosphere of $95 \%$ air: $5 \% \mathrm{CO}_{2}$ at $37^{\circ} \mathrm{C}$ and were sub-cultured at 1:4 split at $\sim 80 \%$ confluency.

Growth parameters. The population doubling time was determined during the exponential growth phase by obtaining the viable cell counts from triplicate flasks at 24, 48, 72 and $96 \mathrm{~h}$ post-seeding of $1.0 \times 10^{5}$ cells per flask, and the mean values from four time points were used to determine the population doubling times. Saturation density was determined from the viable cell number at day 7 post-seeding of $1.0 \times 10^{5}$ cells, and the data were expressed as the means $\pm \mathrm{SD}, \mathrm{n}=6$ per treatment group.

Anchorage-independent colony formation. This assay was performed according to a previously published protocol (12). Briefly, 1,000 MCF-7 cells per $2 \mathrm{ml}$ were suspended in the culture medium containing $0.33 \%$ agar. Cell suspension $(2 \mathrm{ml})$ was overlaid on a basement of $0.6 \%$ agar in each well of 6 -well cluster plates. The cultures were maintained at $37^{\circ} \mathrm{C}$ in a humidified atmosphere of $95 \%$ air:5\% $\mathrm{CO}_{2}$ for 21 days. The cultures with developed anchorage-independent colonies were then fixed in Cornoy's fluid and the colony count in each well was determined microscopically at x 10 magnification. The data were expressed as the means $\pm \mathrm{SD}, \mathrm{n}=12$ per treatment group.

Chemical reagents. $\mathrm{E}_{2}$ and tamoxifen (TAM) were obtained from Sigma Chemical Co. The stock solutions (100 $\mu \mathrm{M})$ of these compounds were prepared in $100 \%$ ethanol and serially diluted in the culture medium to obtain the final working solutions of $20 \mathrm{nM}$ for treatment.

Aqueous extract of $\mathrm{CO}$. To prepare the aqueous extract of $\mathrm{CO}$, $20 \mathrm{~g}$ of the $\mathrm{CO}$ fruit was boiled in $200 \mathrm{ml}$ of de-ionized water until the volume was reduced to $100 \mathrm{ml}$, and the supernatant was collected (Aqueous Extract \#1). The resultant residue was further boiled in $100 \mathrm{ml}$ of water until the volume was reduced to $50 \mathrm{ml}$ (Aqueous Extract \#2). The two supernatants, Extract \#1 (100 ml) and Extract \#2 $(50 \mathrm{ml})$, were combined and concentrated by boiling until the volume was reduced to $25 \mathrm{ml}$. These combined extracts were centrifuged at 5,000 rpm at room temperature for $10 \mathrm{~min}$. The resultant supernatant (20 ml) was collected and stored as stock solution at $-20^{\circ} \mathrm{C}$ in $5 \mathrm{ml}$ aliquots. These stock solutions were appropriately diluted in DME/F12 medium to obtain the working concentrations.

Dose response of $\mathrm{CO}$. For the dose response experiments, MCF-7 cells were seeded at the initial density of $1.0 \times 10^{5}$ cells $/ 25 \mathrm{~cm}^{2}$ in T-25 flasks. Treatment with $\mathrm{CO}$ at $0.01,0.05$, $0.1,0.5,1.0$ and $2.0 \%$ doses was initiated at day 1 post-seeding and continued up to day 7 post-seeding, with a medium change every $48 \mathrm{~h}$. At the end of the treatment schedule, the cultures were trypsinized and trypan blue excluding viable cell counts were obtained. The cell viability data from these dose response experiments were used to identify minimum effective and maximum cytostatic concentrations of $\mathrm{CO}$ relative to the initial seeding density of MCF-7 cells. The data were expressed as viable cell number means $\pm \mathrm{SD}, \mathrm{n}=6$ per treatment group.

Sample preparation for cellular metabolism of $E_{2}$. The MCF-7 cells at day 1 post-seeding were treated with appropriate maximally effective cytostatic concentration of $\mathrm{CO}$ in the presence of $20 \mathrm{nM} \mathrm{E}_{2}$ for $48 \mathrm{~h}$ and the medium was analyzed for $\mathrm{E}_{2}$ metabolites following published methods (13). Briefly, a 5-ml aliquot of the medium was diluted 1:1 with sodium acetate buffer ( $\mathrm{pH} 4.65)$ and $20 \mu \mathrm{l}$ of $\beta$-glucuronidase $\left(110,200 \mathrm{U} / \mathrm{ml}\right.$; Sigma). This solution was incubated at $37^{\circ} \mathrm{C}$ for $24 \mathrm{~h}$ to de-conjugate the steroids. After the addition of deuterated $\mathrm{E}_{2}$ as an internal standard $(14,15)$, each sample was thoroughly vortexed. Two volumes of chloroform were added to the samples and the resulting mixture was vortexed and centrifuged. The chloroform layer was removed and reduced to dryness using a vacuum equipped centrovap console (Labconco, Inc., St. Louis, MO, USA).

Each sample was derivitized by adding $10 \mu 1$ of dry pyridine and $40 \mu \mathrm{l}$ of bis (trimethylsilyl) trifluoroacetamide (BSTFA), vortexed and allowed to react at room temperature 
Table I. Endocrine responsiveness of ER ${ }^{+}$human mammary carcinoma MCF-7 cells.

\begin{tabular}{|c|c|c|c|c|}
\hline \multirow[t]{2}{*}{ Treatment } & \multirow[t]{2}{*}{ Concentration } & \multicolumn{3}{|c|}{ Biomarker } \\
\hline & & $\begin{array}{c}\text { Population } \\
\text { doubling }(\mathrm{h})^{\mathrm{a}}\end{array}$ & $\begin{array}{l}\text { Saturation density } \\
\qquad\left(\times 10^{5}\right)^{\mathrm{b}}\end{array}$ & $\begin{array}{c}\text { Anchorage-independent } \\
\text { colonies }^{c}\end{array}$ \\
\hline Serum & $0.7 \%$ & 33.0 & $11.8 \pm 0.9^{\mathrm{d}}$ & $16.7 \pm 3.4^{\mathrm{g}}$ \\
\hline $\mathrm{E}_{2}$ & $20 \mathrm{nM}$ & 28.5 & $17.9 \pm 1.6^{\mathrm{e}}$ & $37.2 \pm 2.1^{\mathrm{h}}$ \\
\hline TAM & $20 \mathrm{nM}$ & 35.9 & $3.9 \pm 0.6^{\mathrm{f}}$ & $7.7 \pm 0.4^{\mathrm{i}}$ \\
\hline
\end{tabular}

${ }^{a}$ Determined during the exponential growth phase. ${ }^{b}$ Viable cell number at day 7 post-seeding of $1.0 \times 10^{5}$ cells. ${ }^{d-f}$ Means \pm SD, $n=6$ per treatment

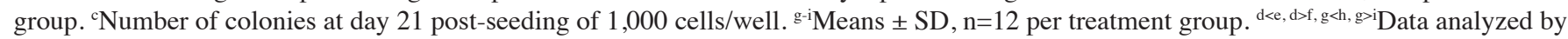
one-way analysis of variance (ANOVA) and Dunnett's multiple comparison test $(\alpha=0.05)$.

overnight. One microliter of each sample was injected into the GC-MS apparatus without further treatment.

$G C-M S$ conditions for analysis of $E_{2}$ metabolites. Select $\mathrm{E}_{2}$ metabolites were analyzed on an Agilent $6980 \mathrm{~N}$ gas chromatograph equipped with an Agilent 5973 mass selection detector, an Agilent 7683 injector and an HP GI701CA MSD Chemstation. The injection port was equipped with a split/ splitless capillary inlet system and a silanized glass insert. The temperature of the injection port was maintained at $300^{\circ} \mathrm{C}$. The GC-MS interface was maintained at $270^{\circ} \mathrm{C}$ and the ion source was maintained at $280^{\circ} \mathrm{C}$. The ionization energy was $70 \mathrm{eV}$. The carrier gas was helium at a flow rate of $1 \mathrm{ml} /$ min. Separations of metabolites were carried out using a Hewlett-Packard Ultra 2 capillary column with cross-linked $5 \%$ phenyl-methyl silicone $(25 \mathrm{~m} \times 0.2 \mathrm{~mm} \times 0.33 \mu \mathrm{m}$ film thickness). The oven temperature was increased from 60 to $260^{\circ} \mathrm{C}$ at $40^{\circ} \mathrm{C} / \mathrm{min}$, then at $1^{\circ} \mathrm{C} / \mathrm{min}$ to $280^{\circ} \mathrm{C}(13-15)$.

Under selected ion monitoring, the following mass ions and GC elution times of trimethylsilylated estrogens were routinely monitored: Estrone $\left(E_{1}\right) \mathrm{m} / \mathrm{z} 342,15.90 \mathrm{~min} ; \mathrm{E}_{2} \mathrm{~m} / \mathrm{z} 416$, $16.40 \mathrm{~min}$; deuterated $\mathrm{E}_{2} \mathrm{~m} / \mathrm{z} 420,16.40 \mathrm{~min}$; 2-hydroxyestrone $\left(2-\mathrm{OHE}_{1}\right) \mathrm{m} / \mathrm{z} 430,18.47 \mathrm{~min}$; 4-hydroxyestrone $\left(4-\mathrm{OHE}_{1}\right)$ $\mathrm{m} / \mathrm{z} 430,18.92 \mathrm{~min} ; 16 \alpha$-hydroxyestrone $\left(16 \alpha-\mathrm{OHE}_{1}\right) \mathrm{m} / \mathrm{z} 286$ and 430, $19.37 \mathrm{~min}$; and estriol $\left(\mathrm{E}_{3}\right) \mathrm{m} / \mathrm{z} 504$ and 345, $20.76 \mathrm{~min}$. The other $\mathrm{E}_{2}$ metabolites, 2-hydroxyestradiol (2-OHE $)$ and 4-hydroxyestradiol (4- $\left.\mathrm{OHE}_{2}\right)$, were monitored using the mass and base ions m/z 504 and 373 at 19.06 and $20.15 \mathrm{~min}$, respectively, in a second run using the same parameters as above. Deuterated estradiol $\left(2,4,16 \alpha, 16 \beta-{ }^{2} \mathrm{H} 4\right)$ was synthesized in our laboratory according to the method of Dehennin et al (14), and was used as the internal standard. The individual metabolites were quantified using a six point calibration curve (range 1-50 ng). The data were expressed as ng metabolite per $10^{6}$ cells.

Modulation of $E_{2}$ metabolism. In the cellular metabolism of $E_{2}, E_{1}$ functions as a common precursor for the formation of $2-\mathrm{OHE}_{1}$ and $16 \alpha-\mathrm{OHE}_{1}$, and the pro-mitogenic $16 \alpha-\mathrm{OHE}_{1}$ is converted in to the mitogenically inert proximate metabolite $\mathrm{E}_{3}$. Therefore, to accurately evaluate the modulation in $\mathrm{E}_{2}$ metabolism, the $2-\mathrm{OHE}_{1}: 16 \alpha-\mathrm{OHE}_{1}$ and $\mathrm{E}_{3}: 16 \alpha-\mathrm{OHE}$ ratios were considered. The $2-\mathrm{OHE}_{1}: 16 \alpha-\mathrm{OHE}_{1}$ ratio was calculated by dividing values of $2-\mathrm{OHE}_{1}$ by those of $16 \alpha-\mathrm{OHE}_{1}$. To deter- mine the proportion of total $16 \alpha-\mathrm{OHE}_{1}$ that is converted to the mitogenically inert $\mathrm{E}_{3}$, the $\mathrm{E}_{3}: 16 \alpha-\mathrm{OHE}_{1}$ ratio was calculated by dividing the values of $\mathrm{E}_{3}$ by those of $16 \alpha-\mathrm{OHE}_{1}+\mathrm{E}_{3}$.

Statistical analysis. Experiments with $\mathrm{E}_{2}$ and TAM were performed using $n=6$ flasks per treatment group. The experiment for dose response of $\mathrm{CO}$ to determine cytostatic growth arrest was performed using $\mathrm{n}=6$ flasks per treatment group, while that for the effect of $\mathrm{CO}$ on anchorage-independent growth was performed with $n=12$ wells per treatment group using 6-well plates. The experiment for $\mathrm{E}_{2}$ metabolism was performed using $\mathrm{n}=3$ flasks per treatment group.

The significance of differences between the control and experimental data points for individual experiment was analyzed by the 2-sample t-test using the Prism 4.0 statistical software (Graph Pad Software, Inc.). The p-values for these data were further analyzed by one-way ANOVA with Dunnett's Multiple Range Test $(\alpha=0.05)$, correcting for multiple comparisons among control group and multiple treatment groups.

\section{Results}

Growth of MCF-7 cells in serum-depleted culture medium. The experiment designed to examine the persistence of endocrine responsiveness of MCF-7 cells in serum depleted culture conditions is presented in Table I. Relative to the cells maintained in $0.7 \%$ serum, those treated with $E_{2}$ exhibited a $13.6 \%$ decrease in population doubling time, a $51.7 \%$ increase in saturation density and a $122.7 \%$ increase in the number of anchorage-independent colonies. By contrast, the cells treated with TAM exhibited a $8.8 \%$ increase in population doubling time, a $66.9 \%$ decrease in saturation density and a $53.9 \%$ decrease in the number of anchorage-independent colonies.

Dose response of $C O$. The experiment presented in Table II identifies the growth inhibitory profile of $\mathrm{CO}$ on $\mathrm{E}_{2}$-stimulated MCF-7 cells. The treatment of $\mathrm{E}_{2}$-stimulated MCF-7 cells with $\mathrm{CO}$ resulted in progressive dose-dependent cytostatic growth arrest of $8.3,35.7$ and $75.1 \%$, respectively, relative to that observed in control cells treated with $\mathrm{E}_{2}$ alone. Thus, the data generated from this experiment identified $0.01 \%$ as minimum effective, and $0.1 \%$ as maximum cytostatic concentrations for $\mathrm{CO}$, relative to the initial seeding density of MCF-7 cells. Treatment with the higher dose of $0.5 \% \mathrm{CO}$, however, resulted 
Table II. Cytostatic growth arrest of ER ${ }^{+}$human mammary carcinoma MCF-7 cells by Cornus officinalis (CO).

\begin{tabular}{lccc}
\hline Treatment & Concentration & Viable cell no. $\left(x 10^{5}\right)^{\mathrm{a}}$ & Inhibition $(\%$ control $)$ \\
\hline $\mathrm{E}_{2}$ & $20 \mathrm{nM}$ & $16.1 \pm 1.6^{\mathrm{b}}$ & - \\
$\mathrm{E}_{2}+\mathrm{CO}$ & $0.01 \%$ & $14.8 \pm 1.5^{\mathrm{b}}$ & 8.3 \\
& $0.05 \%$ & $10.3 \pm 1.0^{\mathrm{c}}$ & 35.7 \\
& $0.10 \%$ & $4.0 \pm 0.7^{\mathrm{d}}$ & 75.1 \\
& $0.50 \%$ & $0.5 \pm 0.1^{\mathrm{e}}$ & 96.9 \\
\hline
\end{tabular}

${ }^{a}$ Determined at day 7 post-seeding of $1.0 \times 10^{5}$ cells. ${ }^{b-d}$ Means $\pm S D, n=6$ per treatment group. ${ }^{b>c, b>d, b>e}$ Data analyzed by Dunnett's multiple comparison test $(\alpha=0.05)$.

Table III. Inhibition of anchorage-independent colony formation in $\mathrm{ER}^{+}$human mammary carcinoma MCF-7 cells by Cornus officinalis (CO).

\begin{tabular}{lccc}
\hline Treatment & Concentration & No. of colonies $^{\mathrm{a}}$ & Inhibition $(\% \text { control })^{\mathrm{E}_{2}}$ \\
$\mathrm{E}_{2}+\mathrm{CO}$ & $20 \mathrm{nM}$ & $38.0 \pm 2.6^{\mathrm{b}}$ & - \\
& $0.01 \%$ & $24.7 \pm 1.6^{\mathrm{c}}$ & 35.0 \\
& $0.05 \%$ & $17.0 \pm 1.1^{\mathrm{d}}$ & 55.3 \\
& $0.10 \%$ & $4.4 \pm 0.5^{\mathrm{e}}$ & 88.4 \\
\hline
\end{tabular}

${ }^{a}$ Determined at day 21 post-seeding of 1,000 cells/well. ${ }^{b-e}$ Means $\pm S D, n=12$ per treatment group. ${ }^{b>c, b>d, b>e}$ Data analyzed by Dunnett's multiple comparison test $(\alpha=0.05)$.

Table IV. Effect of Cornus officinalis $(\mathrm{CO})$ on $17 \beta$-estradiol $\left(\mathrm{E}_{2}\right)$ metabolism in $\mathrm{ER}^{+}$human mammary carcinoma MCF-7 cells.

\begin{tabular}{lccccc}
\hline Treatment & Concentration & \multicolumn{4}{c}{$\mathrm{E}_{2}$ metabolite $^{\mathrm{a}}$} \\
\cline { 3 - 5 } & & $\mathrm{E}_{1}$ & $2-\mathrm{OHE}_{1}$ & $16 \alpha-\mathrm{OHE}_{1}$ & $\mathrm{E}_{3}$ \\
\hline $\mathrm{E}_{2}$ & $20 \mathrm{nM}$ & $7.8 \pm 0.6^{\mathrm{b}}$ & $0.9 \pm 0.2^{\mathrm{d}}$ & $2.2 \pm 0.1^{\mathrm{f}}$ & $0.22 \pm 0.03$ \\
$\mathrm{CO}$ & $0.1 \%$ & $14.4 \pm 1.9^{\mathrm{c}}$ & $5.5 \pm 1.3^{\mathrm{e}}$ & $0.8 \pm 0.2^{\mathrm{g}}$ & $0.20 \pm 0.04$ \\
\hline
\end{tabular}

${ }^{a}$ Nanograms per $10^{6}$ cells. Means $\pm \mathrm{SD}, \mathrm{n}=3$ per treatment group. The metabolites were determined at $48 \mathrm{~h}$ of incubation with $\mathrm{E}_{2}$ alone or with $\mathrm{E}_{2}+$ CO. ${ }^{\mathrm{b}, \mathrm{c}} \mathrm{p}=0.03 ;{ }^{\mathrm{d}, \mathrm{e}} \mathrm{p}=0.01 ;{ }^{\mathrm{f}, \mathrm{g}} \mathrm{p}=0.04$.

in a viable cell number that was lower than the initial seeding density, thus demonstrating a cytotoxic response.

Efficacy of $\mathrm{CO}$ for inhibition of anchorage-independent growth. The experiment presented in Table III was designed to examine the effect of $\mathrm{CO}$ on the number of anchorage-independent colonies. The data generated from this experiment demonstrated that the $\mathrm{E}_{2}$-stimulated increase in the number of colonies was progressively decreased to $35.0,55.3$ and $88.4 \%$ in response to the treatment with $0.01,0.05$ and $0.10 \% \mathrm{CO}$, respectively.

Effect of $\mathrm{CO}$ on estradiol metabolism. The experiment presented in Table IV examined the effect of $\mathrm{CO}$ on the cellular metabolism of $\mathrm{E}_{2}$. The treatment with $\mathrm{CO}$ resulted in a 5.1-fold increase in the anti-proliferative $\mathrm{E}_{2}$ metabolite $2-\mathrm{OHE}_{1}$, a $63.6 \%$ decrease in the pro-mitogenic metabolite $16 \alpha-\mathrm{OHE}_{1}$ and a non-significant $9.3 \%$ decrease in the mitogenically inert metabolite $\mathrm{E}_{3}$ formation, relative to that in the
$\mathrm{E}_{2}$-treated controls. Other biologically active metabolites, such as $4-\mathrm{OHE}_{1}, 4-\mathrm{OHE}_{2}$ and $2-\mathrm{OHE}_{2}$, remained essentially unaltered in the $\mathrm{CO}$-treated group relative to those in the $\mathrm{E}_{2}$-treated control group.

Modulation of estradiol metabolism. The data presented in Table V examined the effect of $\mathrm{CO}$ on the $2-\mathrm{OHE}_{1}: 16 \alpha-\mathrm{OHE}_{1}$ ratio. Relative to the $\mathrm{E}_{2}$-treated controls that exhibited a ratio of $0.44 \pm 0.11$, CO-treated cells exhibited a ratio of $6.84 \pm 0.47$, resulting in a 14.5 -fold increase. The data presented in Table VI examined the effect of $\mathrm{CO}$ on the $\mathrm{E}_{3}: 16 \alpha-\mathrm{OHE}_{1}$ ratio. Relative to the $\mathrm{E}_{2}$-treated control cells that exhibited a ratio of $0.09 \pm 0.02, \mathrm{CO}$-treated cells exhibited a ratio of $0.39 \pm 0.11$, resulting in a 3.3 -fold increase.

\section{Discussion}

Hormone responsive $\mathrm{ER}^{+}$clinical breast cancer is traditionally treated with selective ER modulators, such as TAM, and/or 
Table V.Effect of Cornus officinals (CO) on the ratio of 2-hydroxyestrone $\left(2-\mathrm{OHE}_{1}\right)$ and $16 \alpha$-hydroxyestrone $\left(16 \alpha-\mathrm{OHE}_{1}\right)$.

\begin{tabular}{lcc}
\hline Treatment & Concentration & $2-\mathrm{OHE}_{1}: 16 \alpha-\mathrm{OHE}_{1}$ ratio $^{\mathrm{a}}$ \\
\hline $\mathrm{E}_{2}$ & $20 \mathrm{nM}$ & $0.44 \pm 0.11^{\mathrm{b}}$ \\
$\mathrm{CO}$ & $0.1 \%$ & $6.84 \pm 0.47^{\mathrm{c}}$ \\
\hline
\end{tabular}

${ }^{\mathrm{a}}$ Means $\pm \mathrm{SD}, \mathrm{n}=3$ per treatment group. Data analyzed by 2 -sample $\mathrm{t}$-test compared to the data from the $\mathrm{E}_{2}$-treated control group. ${ }^{\mathrm{b}, \mathrm{c}} \mathrm{p}=0.001$.

Table VI. Effect of Cornus officinalis (CO) on the ratio of estriol $\left(\mathrm{E}_{3}\right)$ and $16 \alpha$-hydroxyestrone $\left(16 \alpha-\mathrm{OHE}_{1}\right)$.

\begin{tabular}{lcc}
\hline Treatment & Concentration & $\mathrm{E}_{3}: 16 \alpha-\mathrm{OHE}_{1}$ ratio $^{\mathrm{a}}$ \\
\hline $\mathrm{E}_{2}$ & $20 \mathrm{nM}$ & $0.09 \pm 0.02^{\mathrm{b}}$ \\
$\mathrm{CO}$ & $0.1 \%$ & $0.39 \pm 0.11^{\mathrm{c}}$ \\
\hline
\end{tabular}

${ }^{\mathrm{a}} \mathrm{E}_{3} /\left(16 \alpha-\mathrm{OHE}_{1}+\mathrm{E}_{3}\right)$. Means $\pm \mathrm{SD}, \mathrm{n}=3$ per treatment group. Data analyzed by the 2-sample t-test compared to the data from the $\mathrm{E}_{2}$-treated control group. ${ }^{\mathrm{b}, \mathrm{c}} \mathrm{p}=0.01$.

cytotoxic chemotherapeutic drugs, such as combinations of alkylating agents, anti-folates, nucleic acid anti-metabolites, anthracyclins and micro-tubule inhibitors $(2,3,16)$. These treatment options are frequently associated with acquired tumor resistance and adverse systemic toxicity, compromising long-term patient compliance. Herbal medicinal products with potential to enhance therapeutic efficacy and reduce toxicity represent an attractive treatment option in complementary and alternative medicine. The long-term safety, efficacy and lack of adverse reactions of herbal medicines with conventional chemo-endocrine therapy is, however, largely unknown.

Human carcinoma-derived cell culture models, such as the $\mathrm{ER}^{+} \mathrm{MCF}-7$ cell line, provide a rapid mechanistic approach to obtain clinically translatable data $(11,12)$. MCF-7 cells adapted for growth in chemically defined serum-depleted medium ( $0.7 \%$ serum, $<1 \mathrm{nM} \mathrm{E}_{2}$ ) exhibited a positive growth regulatory effect of $E_{2}$ at physiologically relevant levels. By contrast, treatment with the prototypic selective ER modulator TAM at the clinically achievable pharmacological concentration resulted in growth inhibition. These data are consistent with the previous observations that in vivo MCF-7 cell transplants in the athymic 'nude' mouse xenotransplant model require $\mathrm{E}_{2}$ for tumor formation, and that systemic administration of TAM inhibits tumor growth $(11,16)$.

Anchorage-independent growth represents a specific and sensitive in vitro surrogate end point biomarker for tumorigenic cell lines $(11,12,17-20)$. In accord, it is noteworthy that $E_{2}$ treatment resulted in an increased number of anchorage-independent colonies, while TAM treatment resulted in decreased colony number. These data on anchorage-independent growth together with those on modulatory effects of $\mathrm{E}_{2}$ and TAM on cell viability provide evidence for persistent endocrine responsiveness of MCF-7 cells adapted for growth in serum-depleted medium.
The data with $\mathrm{CO}$ for induction of cytostatic growth arrest and reduction of carcinogenic risk at relatively low doses taken together identify valuable phenomenological leads for the efficacy of $\mathrm{CO}$ on $\mathrm{ER}^{+} \mathrm{MCF}-7$ cells. The maximally effective low dose may thus provide an acceptable toxicity profile for future animal studies or clinical trials. In this context, it is noteworthy that $\mathrm{ER}^{+} \mathrm{MCF}-7$ cells are also responsive to the growth inhibitory effects of non-fractionated aqueous extracts prepared from other plant products, such as Lycium barbarum and Tabebuia avellandae, and these extracts appear to operate via several mechanisms, including modulation of cellular $E_{2}$ metabolism, as well as altered expression of several target genes for cell cycle progression, cellular apoptosis and xenobiotic metabolism $(21,22)$.

During the Cyp450-mediated oxidative metabolism of $\mathrm{E}_{2}$, this mitogenic hormone is converted via C17-oxidation to $E_{1}$. The intermediate metabolite $E_{1}$ functions as a common precursor either for the formation of $2-\mathrm{OHE}_{1}$ via C2-hydroxylation, or for the formation of $16 \alpha-\mathrm{OHE}_{1}$ via C16 $\alpha$-hydroxylation (23-28). These metabolites have documented distinct growth modulating effects on MCF-7, or other human mammary carcinoma-derived cell lines. In accord, it is noteworthy that treatment of mouse mammary epithelial cells or human mammary carcinoma MCF-7 cells with $\mathrm{E}_{2}$ and $16 \alpha-\mathrm{OHE}_{1}$ resulted in increased anchorage-dependent and anchorage-independent growth, while treatment with 2-OHE resulted in reduction in these parameters (29-31). Additionally, in the MCF-7 xenograft model these treatments produced similar modulations in the tumor size (31). Thus, $2-\mathrm{OHE}_{1}$ has potent anti-proliferative effect, while $16 \alpha-\mathrm{OHE}_{1}$ functions as a pro-mitogenic metabolite (26-33). Data generated from the present study, measuring cellular metabolism of $\mathrm{E}_{2}$, clearly demonstrated that treatment of MCF-7 cells with $\mathrm{CO}$ at the maximally effective cytostatic concentration predominantly affected the C2-hydroxylation pathway, up-regulating the formation of anti-proliferative 2- $\mathrm{OHE}_{1}$.

Overall, the data on cytostatic growth arrest and on modulation of cellular metabolism of $\mathrm{E}_{2}$ by non-fractionated aqueous extract from $\mathrm{CO}$ fruit essentially extend and confirm our recent preliminary observations (32), and thereby identify a mechanistic lead for the efficacy of $\mathrm{CO}$ in $\mathrm{ER}^{+}$human mammary carcinoma MCF-7 cells.

It is well established that Cyp450-dependent conversion of pro-mitogenic $E_{2}$ to mitogenically inert $E_{3}$ is accomplished predominantly via the well-documented $\mathrm{E}_{2}-\mathrm{E}_{1}-16 \alpha-\mathrm{OHE}_{1}-\mathrm{E}_{3}$ pathways (23-26). Thus, in the present study a 14.5 -fold increase in the $2-\mathrm{OHE}_{1}: 16 \alpha-\mathrm{OHE}_{1}$ ratio in response to the treatment with $\mathrm{CO}$ was predominantly due to a specific increase in $2-\mathrm{OHE}_{1}$ formation. In addition, treatment with $\mathrm{CO}$ resulted in a 3.3-fold increase in the $\mathrm{E}_{3}: 16 \alpha-\mathrm{OHE}_{1}$ ratio. This alteration was predominantly due to a specific decrease in $16 \alpha-\mathrm{OHE}_{1}$ formation. Thus, these $E_{2}$ metabolite ratios may represent unique and novel mechanistically distinct biomarkers that quantify alterations in the mitogenecity of $\mathrm{E}_{2}$.

Since $\mathrm{E}_{1}$ functions as a common precursor for the formation of $2-\mathrm{OHE}_{1}$ and $16 \alpha-\mathrm{OHE}_{1}(23-28)$, and because individual $\mathrm{E}_{2}$ metabolites exhibit distinct growth modulating effects (26-33), the ratios of $2-\mathrm{OHE}_{1}: 16 \alpha-\mathrm{OHE}_{1}$ and $\mathrm{E}_{3}: 16 \alpha-\mathrm{OHE}_{1}$ may represent modulatable endocrine biomarkers for carcinogenic risk and, therefore, may identify novel mechanistic quantitative 
parameters for the efficacy of therapeutic/preventive agents In this context, it is noteworthy that our previous studies have demonstrated that human mammary epithelial cells transformed by the clinically relevant HER-2 oncogene, as well as $\mathrm{ER}^{+}$MCF-7 and ER ${ }^{-}$MDA-MB-231 human mammary carcinoma cell lines exhibit a modulatable $2-\mathrm{OHE}_{1}: 16 \alpha-\mathrm{OHE} 1$ ratio that is up-regulated in response to treatment with the naturally occurring phytochemical indole-3-carbinol (34-36).

It is well recognized that traditional herbal medicine uses several herbal preparations in combination, and that individual herbal preparations may contain several biologically active components playing distinct roles in their combined activity. Thus, although non-fractionated aqueous extract from $\mathrm{CO}$ fruit exhibits growth inhibitory effects in the present study, the identity of water soluble components that may be responsible for the observed effects and their putative molecular/mechanistic targets remain currently unknown. In this context, it should be noted that methanolic or aqueous extracts from several distinct species of $\mathrm{CO}$ have documented anti-proliferative, anti-oxidant and anti-inflammatory properties $(37,38)$.

In conclusion, the data generated in the present study have identified distinct phenomenological and mechanistic leads for the efficacy of CO. Thus, the outcome of this study has validated a rapid mechanism-based approach to prioritize efficacious herbal medicinal products for the treatment of $\mathrm{ER}^{+}$ clinical breast cancer.

\section{Acknowledgements}

Major funding for this study was provided by philanthropic contributions to the American Foundation for Chinese Medicine, from Peter Cheney, Suzanne Hoyt, the family of Daniel and Kathleen Mezzalingua, the family of Hakan and Marie Ledin and by the Issac and Laura Perlmutter Fund. The study is dedicated to the memory of Laurie Mezzalingua (1968-2009).

\section{References}

1. Siegel R, Ward E, Brawley O, et al: Cancer Statistics-2011. CA Cancer J Clin 61: 212-236-, 2011.

2. Lippman ME: Efforts to combine endocrine and chemotherapy in the management of breast cancer: do two and two equals three? Breast Cancer Res Treat 3: 117-127, 1983.

3. Early Breast Cancer Trialist's Group (EBCTG): Effects of chemotherapy and hormonal therapy for early breast cancer on recurrence and 15 years survival: an overview of the randomized trials. Lancet 365: 1687-1717, 2005.

4. Molassiotis A, Scott JA, Kearney A, et al: Complementary and alternative use in breast cancer patients in Europe. Support Care Cancer 14: 206-267, 2006.

5. Rock E and DeMichele A: Nutritional approaches to late toxicities of adjuvant chemotherapy in breast cancer survivors. J Nutr 133: S3785-S3793, 2003.

6. Hyler LK, Chin S, Chui BK, et al: The use of complementary and alternative medicines among patients with locally advanced breast cancer - a descriptive study. BMC Cancer 6: 39-46, 2006

7. Tindle HA, Davis RB, Phillips RL, et al: Trends in the use of complementary and alternative medicines by US adults: 1997-2002. Altern Ther Health Med 11: 42-49, 2005.

8. Cao GW, Yang WG and Du P: Observations of the effects of LAK/IL-2 therapy combining with Lycium barbarum polysaccharides in treatment of 75 cancer patients. Zhonghua Zong Liu Zha Zhi 16: 428-431, 1994 (In Chinese).

9. Gan L, Hua Zhang S, Liang Yang X and Bi Xu H: Immunomodulation and anti-tumor activity by a polysaccharide-protein complex from Lycium barbarum. Int J Immunopharmacol 4: 563-569, 2004
10. Zhou S-F: Chinese herbal medicines for toxicity reduction in cancer chemotherapy. Aust J Acupunct Chinese Med 2: 30-31, 2007.

11. Lippman ME, Osborne CK, Knazek R and Young N: In vitro model systems for the study of hormone-dependent human breast cancer. N Engl J Med 296: 154-159, 1977.

12. Suto A, Bradlow HL Kubota T, et al: Alteration in proliferative and endocrine responsiveness of human mammary carcinoma cells by prototypic tumor-suppressing agents. Steroids 58: 212-219, 1993.

13. Sepkovic DW, Bradlow HL, Michnovicz J, et al: Catachol estrogen production in rat microsomes after treatment with indole-3-carbinol, ascorbigen, or $\beta$-napthaflavone: a comparison of stable isotope dilution, gas chromatography-mass spectrophotometry and radiometric methods. Steroids 59: 318-323, 1994.

14. Dehenin L, Reiffsteck A and Scholler R: Simple methods for the synthesis of twenty different highly enriched deuterium labeled steroids suitable as internal standards for isotope dilution mass spectrometry. Biochem Mass Spectrometry 7: 493-499, 1980

15. Raju U, Sepkovic DW, Dixon JM, et al: Estrone and estradiol metabolism in vivo in human breast cysts. Steroids 65: 883-888, 2000.

16. Jordan VC: Historical perspective on hormonal therapy of advanced breast cancer. Clin Ther 24: A3-A16, 2002.

17. Suto A, Bradlow HL, Wong GY, et al: Persistent estrogen responsiveness of Ras oncogene transformed mouse mammary epithelial cells. Steroids 57: 262-268, 1992.

18. Telang NT, Narayanan R, Bradlow HL and Osborne MP: Coordinated expression of intermediate biomarkers for tumorigenic transformation of Ras transfected mouse mammary epithelial cells. Breast Cancer Res Treat 18: 155-163, 1991.

19. Telang NT, Osborne MP, Sweterlitsch LA and Narayanan R Neoplastic transformation of mouse mammary epithelial cells by deregulated myc expression. Cell Regul 1: 863-872, 1990.

20. Telang $\mathbf{N}$ and Katdare M: Novel cell culture model for prevention of carcinogenic risk in familial adenomatous polyposis syndrome. Oncol Rep 21: 1017-1021, 2009.

21. Li G, Sepkovic DW, Bradlow HL, Telang NT and Wong GYC: Lycium barbarum inhibits growth of estrogen receptor-positive human breast cancer cells by favorably altering estradiol metabolism. Nutr Cancer 61: 408-414, 2009.

22. Mukherjee B, Telang NT and Wong GYC: Growth inhibition of estrogen receptor positive human breast cancer cells by Taheebo from the inner bark of Tabebuia avellande tree. Int J Mol Med 24: 253-260, 2009.

23. Schneider J, Kinne D, Frachia A, et al: Abnormal oxidative metabolism of $17 \beta$-estradiol in women with breast cancer. Proc Natl Acad Sci USA 79: 3047-3051, 1982.

24. Fishman J, Schneider J, Herschkopf RJ and Bradlow HL: Increased estrogen $16 \alpha$-hydroxylase activity in women with breast and endometrial cancer. J Steroid Biochem Mol Biol 20: 1077-1081, 1984

25. Yager JD and Davidson NE: Estrogen carcinogenesis in breast cancer. N Engl J Med 354: 270-282, 2006.

26. Castagnetta LM, Granata OM, Cocciadiferro L, et al: Sex steroids, carcinogenesis and cancer progression. Ann NY Acad Sci 1028: 233-246, 2004.

27. Fishman J, Osborne MP and Telang NT: The role of estrogens in mammary carcinogenesis. Ann NY Acad Sci 768: 91-100, 1995.

28. Telang NT: Oncogenes, estradiol metabolism and mammary carcinogenesis. Ann NY Acad Sci 784: 277-287, 1996

29. Lottering ML, Haag M and Segers JC: Effects of 17ß-estradiol metabolites on cell cycle events in MCF-7 cells. Cancer Res 52: 5926-5932, 1992.

30. Telang NT, Suto A, Wong GY, et al: Induction by estrogen metabolite $16 \alpha$-hydroxyestrone of genotoxic damage and aberrant proliferation in mouse mammary epithelial cells. J Natl Cancer Inst 84: 634-638, 1992.

31. Suto A, Telang NT, Tanino H, et al: In vitro and in vivo modulation of growth regulation in the human breast cancer cell line MCF-7 by estradiol metabolites. Breast Cancer 6: 87-92, 1999.

32. Telang NT, Sepkovic DW, Bradlow HL and Wong GYC: Chinese herb Fructus Cornii exhibits preventive efficacy in a cell culture model for hormone responsive breast cancer. Cancer Res 70: S152-S153, 2010.

33. Schneider J, Huh MM, Bradlow HL and Fishman J: Anti-estrogen action of 2-hydroxyestrone on MCF-7 human breast carcinoma cells. J Biol Chem 259: 4840-4845, 1984. 
34. Telang NT, Katdare M, Bradlow HL and Osborne MP: Cell cycle regulation, apoptosis and estradiol metabolism: novel end point biomarkers for human breast cancer prevention. J Clin Ligand Assays 23: 130-137, 2000.

35. Telang NT, Katdare M, Bradlow HL, et al: Inhibition of proliferation and modulation of estradiol metabolism: novel mechanisms for breast cancer prevention by the phytochemical indole-3-carbinol. Proc Soc Exp Biol Med 216: 246-252, 1997.

36. Tiwari RK, Li G, Bradlow HL, et al: Selective responsiveness of human breast cancer cells to indole-3-carbinol, a chemopreventive agent. J Natl Cancer Inst 86: 126-131, 1994.
37. Seeram NP, Schutzki R, Chandra A, et al: Characterization, quantification and bio-activity of Anthocyanins from Cornus species. J Agri Food Chem 50: 2519-2523, 2002.

38. Chang JS, Chiang LC, Hsu FF and Lin CC: Chemoprevention against hepato-cellular carcinoma of Cornus officinalis in vitro. Am J Chinese Med 32: 717-725, 2004. 